\title{
Study on the Three Step of the China's Western Region Economic Development
}

\author{
Hsiung-shen Jung \\ Department of Applied Japanese, Aletheia University, New Taipei City, Taiwan
}

\section{Email address:}

au4210@mail.au.edu.tw

\section{To cite this article:}

Hsiung-shen Jung. Study on the Three Step of the China's Western Region Economic Development. Science Innovation. Vol. 6, No. 1, 2018, pp. 15-19. doi: 10.11648/j.si.20180601.14

Received: December 31, 2017; Accepted: February 26, 2018; Published: March 9, 2018

\begin{abstract}
Modern China 's western development has three important periods: 1) the anti-Japanese war period during the Republican government era; 2) the "three-line construction" period before the "reform and opening up"; 3) the "western development" period after the "reform and opening up". The three different backgrounds, as well as varied domestic and international environments, have led to three different results. In recent years, under the background of the " Asia Pacific rebalancing strategy" in the United States, the "One Belt and One Road" that has been heading for the development of Europe and Africa has given new opportunities for the fourth development in western China.
\end{abstract}

Keywords: The Anti-Japanese War Period, Three-Line Construction, Reform and Open-up Policy, The Western Development, One Belt and One Road

\section{中国西部地区经济发展的三个历程之探讨}

\section{荣雄生}

应用日语学系, 真理大学, 新台北市, 台湾

邮箱

au4210@mail.au.edu.tw

摘要：近代中国对西部的开发有三个重要时期。一是国民政府时代的抗战时期，二是“改革开放”前的“三线建设”，三 是“改革开放”后的“西部大开发”。三个不同时代背景及不同中国内外环境下造就了三个不同的结果。近年，在美国“亚 太再平衡”战略的背景影响下，朝向欧非前進的“一带一路”，給予了中国西部第四次开发的新契机。

关键词：抗战时期, 三线建设, 改革开放政策, 西部大开发, 一带一路

\section{1. 引言}

中国第一次对西部开发的抗战时期, 大量的人力及物 力西移带动了西部的建设, 但是随着抗战结束, 建设也戛 然而止。第二次是1960年代中期至70年代中期为防止美苏 的入侵而耗费大笔资金推行的“三线建设”，它促使西部建 设再次热络。但是受到“文化大革命”等政治斗争的因素影 响, 无法顺利发展经济。1970年代后期开始的“改革开放”
政策，自2000年提出的“西部大开发”计画启动了第三次的 西部开发及建设。相较于两次, 第三次不仅有了具体成效, 也替“一带一路”打下推展的基础。

\section{2. 文献回顾}

申晓云(2007)认为国民政府时期中国大地曾掀起过 两次西北建设的热潮, 一次是在抗战前的 30 年代初, 一 
次是在抗战时的 40 年代。战前的西北开发是国民政府有 计画从事大规模国家工业化建设的开端, 而战时的西北 开发则为抗战建国的重要组成部分[1]。袁佳红(2014)认 为国民政府的抗战大后方调查史料对日后的西部开发 甚至对 “西部大开发”有明确的启发性作用 [2]。耿曙 (2001)、陈东林(2012)、朱民强(2013)认为“三线建设”对 西部的建设或布局有助益。耿曙(2001)甚至认为“三线建 设”的发展策略重于战略考量[3]。曹爆阳(2011)则意指 中国有打仗的准备而有 “三线建设”, 以致美苏放弃发动 侵略战争 [4]。汪红娟(2009)指出“三线建设”虽然成绩显 著，但并不完全成功，中国在整个“三线建设”过程中投 入了大量资金, 却没有从根本上改变西部地区的落后面 貌[5]。

陈东林(2002)指出1983年中央确定了三线企业“调整 改造, 发挥作用”的方针。1986年开始, 历经三个五年计 画, 从布局、产品方向、产业结构和技术改造几个方面, 对三线企业进行了调整改造, 改善了企业的外部环境, 稳 定了职工和科研队伍, 促进了企业的技术进步和体制转变, 增强了企业市场竞争能力, 为建设社会主义市场经济和 “西部大开发”战略提供了重要准备[6]。

陆张维等(2013)认为从社会经济产出的角度看, “西部 大开发”战略实施以来, GDP重心、人均GDP重心、城市 化率重心和工业增加值重心整体呈现向西移动的趋势。 2003年之前, 中国的工业重心仍在向东移动, 2003年之后, 工业重心开始快速向西移动[7]。刘世庆、许英明(2013)指 出2011年9月, 中国国务院总理李克强在乌鲁木齐出席中 国一亚欧经济发展合作论坛致辞中明确提出: 向西开放是 中国全方位对外开放的重大举措。2012年4月，他在莫斯 科大学的演讲说: 中国在扩大对外开放进程中实施扩大内 需战略, 深入推进“西部大开发”, 加快中西部地区发展, 把沿边开放、向西开放做为新一轮开放的重点 [8]。宋志辉 (2015)认为近年来由于美国实施“重返亚太”和“亚太再平 衡” 战略, 不断挤压中国的战略空间, 中国周边形势发生 了巨大的变化, 许多新的情况和新的问题不断出现, 迫使 中国对西部大开发战略进行升级 [9]。

\section{3. 资料分析}

中国西部的开发阶段, 依各学者而不同。陈东林 (2001)区分为50年代以“一五”计画为中心的第一次西部 开发、以“三线建设”为中心的第二次西部开发及1999年 6月9日, 中国国家主席江泽民在中央扶贫开发工作会议 上宣布的第三次“西部大开发”[10]。谢斌(2001)区分为抗 日战争时期、“一五”时期、“三线建设”时期、“西部大开 发”等四次[11]。刘秉扬(2002)区分为“洋务运动”时期、 国民政府成立初期、抗日战争时期等三次 [12]。本文区 分为国民政府时代、“改革开放”前及“改革开放”后三个 时期。

\section{1. 国民政府时代的西部开发}

本文将中国西部开发分为西北及西南。冯成杰(2014) 认为西北开发先后出现两次高潮。沈阳事变后, 第一次掀
起西北开发热潮。自东北沦陷后, 对于西北之开发倍加注 意, 前往考察者日多。1937年7月, 抗日战争全面爆发, 国民政府内迁至重庆，西南、西北两大区域成为沿海工业 迁移的目的地。国民政府则大倡开发西北，在政府和民间 力量的努力推动下, 出现西北开发的第二次热潮 [13]。

同样地处西部, 为何西北比西南较先获得开发。根据 李云峰、曹敏(2003)的汇整, 由于九一八事变、一二八事 变、伪满洲国、华北事变, 中国各界发出“开发西北”的呼 声, 认为西北是中华民族的出路, 要恢复中国版图, 必须 以中华民族发祥地的西北做大本营, 要集中全力来开发西 北。1932年3月, 国民党四届二中全会通过决议, 决定以 长安为陪都, 定名为西京。可以说, 从九一八事变到七七 事变以前, 国民政府的战略构想是以西北作为未来对外战 争的战略基地的。不过在1935年底以后, 随着中国币制的 统一和川、黔、滇等省地方实力派的“中央化”, 国民政府 遂将西南与西北相提并论[14]。

1935年8月1日，国民政府军事委员会主席蒋介石亲自 致函翁文影, 要求资委会从速指派人员筹备四川重工业建 设。政府经济建设重心由西北向西南的转移, 同样也使处 于推进期的西北建设大打折扣。抗战开始后, 西南地区成 为国民政府中枢重心所在地, 西北建设虽未完全终止, 但 推进步骤明显放慢[15]。一語言之, 日本侵華迫使中国開 始了第一次西部的大量開発。

笔者认为西北比西南较先获得开发, 丰富天然资源的 军事考量也是原因之一。李云峰、曹敏(2003)提到甘肃玉 门油矿和新疆独山子油矿 [16]。在物资菒乏的的抗战时期, 这两个油矿提供了大后方军事及经济发展的需要。

在西南建设方面, 李军(2000)指出截至1940年, 西南 已建成各级公路 27,000 公里, 较战前增长了 3 倍。正在赶 筑的也有 2 万公里。新建的 3 条国际公路, 第一、修筑桂越 新线一岳车公路, 于1940年2月通车。第二、滇缅公路, 于1937年冬开工, 7个月完成通车。第三、中印公路 [17]。

1937年11月，国民党政府开始了厂矿的西迁，总计共 有600多家工厂迁到了内地。另外, 国民党政府八年间共 修筑了湘桂、湘黔、黔昆、宝天等铁路, 共计 1,900 多公 里, 另测量铁路线 5,814 公里。修筑的国际公路有: 桂越、 滇缅、滇越、中部及甘新五大干线, 另外还新建公路 11,675 公里, 改善公路88,901公里[18]。

国民政府迁都重庆后，对西部农业、经济、矿产等方 面进行统计研究, 并依此对各领域做出相应的政策, 这些 举措在客观上促进了西部的发展。这些调查在“西部大开 发”中被又一次引用, 并在此基础上深入发展。如抗战时 期对成渝铁路的规划和沿线经济调查，促成1950-52年成 渝铁路的成功修建。1995年建成的成渝高速公路, 也是在 这一调查基础上修建成的第一条四川重庆高速 [19]。

从上述资料来看, 国民政府时代的西部开发契机, 主 要是为“勘内乱、御外侮”, 也就是因军事因素而进行的开 发。在日本侵华初期的西部开发是以西北为主, 抗战开始 前即由西北转移至西南。这些为了跟中国国外联络或军事 补给而建设的铁公路, 不仅在战时发挥其军事作用, 在战 后也继续提供其经济上的功能。另外，国民政府时代的西 部开发除了在交通建设等硬体方面外, 对各方面进行调查 
的史料, 不仅对日后的西部建设有正面影响, 也成为日后 西部开发重要的参考依据。

\section{2. “改革开放”前的西部开发}

1951年2月，中共中央开始编制“一五”计画，编制者 们确定了优先发展重工业的构想。但是, 在当时的国际环 境下, 以苏联为首的社会主义阵营是获取援助的唯一国际 来源。1952年8月, 中国国务院总理周恩来率团赴苏商谈 “一五”计画和中国工业化建设问题。苏联斯大林总書記明 确表示苏联将支持和援助中国以重工业为中心的“一五” 计画[20]。“一五”时期苏联援建的“156项工程”(实际施工 只有 150 项)中, 内地为 118 项, 沿海仅为 32 项。建成了宝 成、成渝、兰新等铁路干线及康藏、青藏公路的建成通车 初步改变了西部地区工业落后和交通闭塞的状况。“一五” 时期对西部地区的初次开发, 对改变该地区的落后面貌, 促进西部地区的经济发展, 初步改变生产力布局的不平衡 性, 缩小东西部地区的发展差距都有重大意义[21]。

中国从施行社会主义经济至改施行市场经济为止的 时期，对西部开发贡献最大的就是“三线建设”。1964年4 月, 中共中央军委总参作战部的一份报告指出：(1)工业过 于集中。(2)大城市人口多。(3)主要铁路枢纽、桥梁和港 口码头, 多在大中城市及其附近, 易遭轰炸破坏, 缺乏应 付敌人突袭的措施。战争初期, 可能陷入瘫疾[22]。1964 年5月, 中国国家主席毛泽东在中共中央会议上明确指出 要下决心搞“三线建设”[23]。无奈美国发动了侵略越南的 战争, 与此同时, 印度不断与中国发生冲突, 在中印边

境东、西两段同时发动大规模的武装进攻。此外, 1969 年, 中苏双方在珍宝岛发生严重流血事件, 各自进入高度 的备战状态。这使得中国无法安心进行和平经济建设[24]。

但是“三线建设”仍获致部分成果。王庭科(2000)认为 “三线建设”(1)改善了中国工业布局极不平衡的状况, 奠定 了西部工业的基础。到70年代末, 建成了 30 多个工业基地, 基本形成了一个具有一定规模, 以重工、军工為主体, 门 类比较齐全的战略后方基地。(2)改善了西部地区的交通闭 塞状况。在“三线建设”时期, 新建了成昆、川黔、襄渝、 湘黔、焦枝等 8,000 多公里的铁路干线, 修建了 25 万公里 的公路。(3)使一批新兴工业城市在西部崛起。这批新兴工 业城市在今天的“西部大开发”中将成为经济增长的要素 聚集点和辐射源。(4)当年“三线建设”者们无私奉献的精神, 为人们留下了一份宝贵的精神遗产 [25]。但是由于对战争 形势估计过于严重和“文革”的干扰，这次以“三线建设”为 形式的西部开发建设规模铺得过大, 战线拉得过长, 超过 了国家的承受能力。其次, 有些项目未进行资源环境的调 查和论证, 就勿忙动工, 造成了严重后患。第三、忽视经 济效益和长期生产要求。一些现代化企业按“靠山、分散、 进洞”的原则建设在山沟里, 造成生产管理、协作十分不 便。第四、在“文革”的干扰下，不惜代价地片面追求政治 目标, 打乱了正常的经济管理制度, 造成了不应有的损失 和浪费 $[26]$ 。

“三线建设”的提出打乱了中国科学院自身发展的目 标和节奏: 旨在提高三线地区研究机构在全院研究机构中 所占比例的指导思想, 显然与根据西南西北地方资源特点
设立科研机构的思路完全不同; “靠山、分散、隐蔽”的选 址和建设思路干扰了此前提出的“三、五成群, 以便于联 系，便于管理”的布局思路。1964年开始的“四清运动”， 特别是1966年开始的“文化大革命”, 这些政治运动打乱了 中国科学院的正常科研工作部署, 使得中国科学院的日常 工作进入一种非常态的状态之中[27]。以交通建设为主的 “156项工程” (内地为 $118 / 150$ 项, 沿海为 $32 / 150$ 项), 可说是 “改革开放”前首次的西部开发。交通及产业同时并进的 “三线建设”, 从最初的军事考量到后来受到政治干扰来看, 虽然投入与产出并未获得平衡, 学者的评价也毁誉参半, 但是去除军事考量、政治干扰，“三线建设”对西部地区的 基础建设及尔后的经济发展仍有其贡献。冷战的战争威胁, 造成了中国第二次西部的大量開発。

\section{3. “改革开放”后的西部开发}

20 世纪 80 年代开始, 随着“改革开放”的实施, 建设重 心转而移至东部。于是这个耗费庞大的人力、财力、物力 却没有获得相对成果的“三线建设”乃嘎然而止。但是, 1983年12月3日，中国国务院下达的关于成立“三线建设” 调整改造规划办公室的通知, 做出如下决定：(1)“三线建 设”调整的方针为: 调整改造, 发挥作用。(2)成立国务院 三线建设调整改造规划办公室, 由相关部委和省市组成。 (3)调整规划的范围:先对云南、贵州、四川(包括重庆市)、 陕西四省和豫西、鄂西地区内的工业交通企业入规划范围 [28]。即使如此, 在国家政策的主导下, 外资迅速进驻东 部沿海地区, 西部地区却未雨露均沾。

在中国国家主席邓小平“两个大局”的考量下，“改革 开放”实施的初期, 西部开发被暂时搁置, 全中国致力于 东部的建设。但是在东部实施成功后, 为平衡东西差距, “西部大开发”乃被提出。第三次的西部开发并未如前两次 因为受到外国军事威胁而被动进行。是在未受到外在因素 影响下, 以经济为考量主动进行的“西部大开发”。

“西部大开发”在“十五”规画被定位是根据江泽民的 提倡。《“西部大开发”“十二五”规画》中所提及项目种类 繁多, 若仅就交通建设, 陆路方面有多条铁公路的建设。 水路方面有航道整治、港区建设、通航设施建设、拓展港 口功能。空路方面有机场的改扩新建[29]。小川春男(2005) 认为“西部大开发”计画的必要性有以下4个原因: (1)所得 差距扩大。(2)经济成长及资源・能源 - 环境保护。(3)宏 观经济调控。(4)国际环境[30]。

沙景华、相楠(2009)指出西部地区发展的SWOT。存 在的问题(Weakness): (1)产业结构不合理。三次产业结构 不合理, 第一产业比重较高; 第二产业发展技术装备水平 较低; 第三产业发展有很大发展潜力。(2)基础设施较比薄 弱。(3)对外经济贸易能力较差。由于地理及历史原因, 西 部对外进出口贸易水平低, 吸引外资的能力很差, 外商投 资以及进出口商品受到限制。(4)自有资金积累能力低、人 才不足和人才流失现象严重。优势(Strength): (1)丰富的资 源。(2)对外合作和贸易。西部可充分利用其国境优势, 参 与国际国内分工, 发展西部经济对外贸易引进国际投资, 拉动经济增长。(3)自然和人文环境。西部地区旅游资源类 型全、品位高、特色与垄断性强, 而且西部地区旅游资源 
分布广泛, 自然和人文景观交相辉映, 旅游业发展潜力大。 面临的机遇(Opportunity): (1)充分利用“西部大开发”战略。 (2)抓住东部地区产业转移。(3)积极参与国际经济一体化。 西部在劳动密集型产业和资源密集型产业上具有国际分 工的比较优势, 国际经济一体化有利于西部地区比较优势 的发挥 [31]。而相较于西部地区人才丰沛、资金雄厚、技 术水平高的东部地区则可视为文中未提到的威胁(Threat)。 虽然姚蕴慧(2006)悲观的认为中西部开发有以下要面 对的问题: 不平衡与不平等的社会、阶层发展与冲突、三 农(农民、农村、农业)问题、社会稳定与社会整合、全球 化背景下的中西部开发[32]。但是, 在“西部大开发”的鼓 吹下, 加上面对沿海地区的生产成本不断提高的情况, 外 资已将目光朝向人力成本较沿海地区低廉且资源丰富内 陆地区, 因此, 在吸取及累积前两次的经验后, 西部内陆 的第三次开发潮的到来值得期待。跟国民政府时代及“改 革开放”前比起来, “改革开放”后的开发成果最为丰富。 同时, 也逐步拉近了存在已久的东西差距。

2013年9月3日, 中国国家主席习近平在哈萨克提到的 丝路经济带的建设以及同年 10 月 3 日在印尼(国会)提到的 21 世纪海上丝路的建设[33]。这就是所谓的“一带一路”。 这个政策将会为未来的中国西部开创更多的商机。西部地 区虽然没有出海港, 但是从中亚经欧洲再延伸至非洲的消 费人口, 将会提供西部地区庞大的市场。另外, 2014年12 月24日, 21 个首批创始成员国的财长和授权代表日在北京 签约共共同决定成立亚洲基础设施投资银行 [34]。翌年的 12月25日正式成立[35]。亚投行的成立, 不论对“西部大开 发”或“一带一路”的资金面都有极大正面的助益。

\section{4. 结论}

国民政府时代由于中国内部有共产党作对，外部有日 本侵略, 因此当时的西部开发是以建设大后方为目的而实 施。亦即, 在有实际的外患及实际的内乱影响下的开发是 以跟外国联系的交通建设为主。

“改革开放”前的西部开发, 主要是在内部有政治斗争, 外部有军事威胁的环境下进行的“三线建设”。如果归纳 “三线建设”的得失, “得”是对西部建设或布局及之后的“改 革开放”更加有助益。“失”是当时为配合“三线建设”而从东 部抽调庞大的人力、物力、财力投入西部, 使得原本经济 条件較佳、经济效益較高的东部丧失了絕佳的发展良机。

虽然“改革开放”初期，中国将开发政策的重点放在东 部地区，但是进入1990年代，中国的对外开放从沿海扩大 到内陆, 西部地区开始有了新的局面。“改革开放”后的西 部开发，区域内有优惠政策，区域外有大量资金，在既无 实际的也无假想的外患内乱的情势下, 第三次的西部开发 迅速进行并获致有效成果。虽然盛況仍不及东部地区, 但 随着今后经济发展的扩大, 届时西部地区的资源开发上的 优势将逐渐显现。再加上, 相对于沿海地区的人事成本较 低, “一带一路”的推展, 内陆地区的再一次开发潮的到来 将指日可待。

从经济地理的角度来看, 地处边陲且交通不便的西部 地区，无论是国民政府时代、“三线建设”时期亦或“改革
开放”后的中国，西部无疑是中国的地区建设及开发的终 点。但是从“一带一路”的视野来看, 位处中国边陲的西部 地理位置却俨然位居东亚与中亚、西亚、南亚的中心位置。 凭借这个优越的地理位置, 加上中国政府的大力倡导, 以 往被认为是中国投资开发终点的西部地区将成为“一带一 路”建设及开发的起点。

\section{参考文献}

[1] 申晓云, 2007, 抗日战争时期国民政府的西北开发 [J], 浙 江大学学报 第 37 卷 第 5 期, 105 。

[2] 袁佳红, 2014, 抗战大后方调查史料的特征与价值[J], 图 书与情报 2014年 第5期，144。

[3] 耿曙, 2001, 「三线建设」始末: 大陆西部大开发的前驱 [J], 中国大陆研究 第44卷 第12期, 1-20。陈东林, 2012, 评价毛泽东三线建设决策的三个新视角 [J], 毛泽东邓小平 理论研究第8期, 80。朱民强, 2013, 总体布局视域下毛泽 东三线建设研究 $[\mathrm{M}]$, 谷牧回忆录, 北京: 中央文献出版社。

[4] 曹显阳, 2011, 新中国成立后毛泽东对战争威胁的判断 [J], 军事历史 第1期, 64-67。

[5] 汪红娟, 2009, 三线决策与西部开发 $[\mathrm{J}]$, 赤峰学院学报第 30 卷第 3 期, 24 。

[6] 陈东林, 2002, 走向市场经济的三线建设调整改造[J], 当 代中国史研究 第 9 卷第 3 期, 42 。

[7] 陆张维、徐丽华、吴次芳、岳文泽, 2013, 西部大开发战 略对于中国区域均衡发展的绩效评价 $[\mathrm{J}]$, 自然资源学报第 28 卷第 3 期, 364 。

[8] 刘世庆、许英明, 2013, 向西开放: 中国新一轮西部大开 发的重点与突破 [J], 经济与管理评论 2013年第3期, 128。

[9] 宋志辉, 2015, 以“丝绸之路经济带”大战略深入推进西部 大发展 $[J]$, 南亚研究季刊 2015年 第1期总第160期, 53。

[10] 陈东林, 2001, 中国共产党三代集体领导的西部开发思想 与实践 $[\mathrm{J}]$, 当代中国史研究 第8卷第4期, 77-85。

[11] 谢斌, 2001, 西部开发与政府行为研究[M], 陕西人民出版 社, 3-24。

[12] 刘秉扬, 2002, 中国近代西部开发动因与效益介析 $[\mathrm{J}]$, 西 北大学学报第 32 卷第 1 期, $16 、 17$ 。

[13] 冯成杰, 2014, 民国时期学界移民剭殖西北思想的构建 [J], 农业考古2014年第3期，103、104。

[14] 李云峰、曹敏, 2003, 抗日时期的国民政府与西北开发 [J], 抗日战争研究, 2003年第3期, 54-57。

[15] 申晓云, 2007, 前揭书[J], 106。

[16] 李雲峰、曹敏, 2003, 前揭書 $[J], 69 、 70$ 。

[17] 李军, 2000, 试论抗战时期大后方交通建设的特点 $[\mathrm{J}]$, 邢 台师范高专学报第 15 卷第 2 期, $22 、 23$ 。 
[18] 谢斌, 2001, 前揭书[J], 4-6。

[19］袁佳红, 2014, 前揭书[J], 144。

[20] 马立新, 2009, 影响50年代中国由新民主主义向社会主义 提前过渡的国际因素 $[J]$, 经济研究导刊2009年第1期总第39 期， 215 。

[21] 谢斌, 2001, 前揭书[J], 9-12。

[22] 总参作战部的报告(1964年4月25日)[R], 党的文献, 1995。

[23] 薄一波, 1993, 若干重大决策与事件的回顾下 $[M]$, 北京: 中共中央党校出版社。

[24] 汪红娟, 2009, 前揭书[J], 22。

[25] 王庭科, 2000, 三线建设与西部大开发 [J], 党的文献, 2000 年第6期总第78期，64、65。

[26] 陈东林, 2001, 前揭书[J], 81、82。

[27] 刘洋、张藜, 2012, 备战压力下的科研机构布局-以中国科 学院对三线建设的早期应对为例 $[\mathrm{J}]$, 中国科技史杂志第33 卷第4期, 446 。
[28] 李彩华, 2002 , 三线建设调整改造的历史考察 $[\mathrm{J}]$, 当代中 国史研究第9卷第3期, 45。

[29] 国家发展和改革委员会, 2012, 西部大开发“十二五”规画 $[R]$ 。

[30] 小川春男, 2005, 中国西部大开发计画得有效性 $[\mathrm{J}]$, 国际 关系纪要第14巻第2号, 2-6。

[31] 沙景华、相楠, 2009, 西部地区经济发展纵横比较分析[J], 世界科技研究与发展第 31 卷第 1 期, $185 、 186$ 。

[32] 姚蕴慧, 2006, 中国大西部开发背后的社会危机 [J], 通识 研究集刊第10期, 开南大学通识教育中心, 105-116。

[33] 江原规由, 2014, 做为中国的对外开放新战略的21世纪丝 路FTA建设 [J] 季刊国际贸易与投资 Summer 2014/No.96, 142 。

[34] 文汇报，2014年12月25日[N]。

[35] 美中时报, 2015年12月25[N]。 